\title{
Profile of Indian women requesting reversal of sterilisation
}

\author{
Manju Puri, MD, Associate Professor; Sandhi Jain, MS, Senior Resident, Department of Obstetric and Gynaecology, Lady \\ Hardinge Medical College and Associated Hospitals, New Delhi, India; PT. BDS PG Institute of Medical Sciences, Rohtak, \\ India.
}

Correspondence: Dr Manju Puri, House No. 140, Sector 14, Rohtak (Haryana), India. Tel: 01262-72014, 72792.

(Accepted April 24 $\left.4^{\text {th }}, 2000\right)$

\begin{abstract}
Summary
This is a prospective clinical study carried out on 96 tubectomised women referred for microsurgical reversal to the Pandit BDS Postgraduate Institute of Medical Sciences, Rohtak and LHMC and SSKH, New Delhi. It was concluded that in developing countries high perinatal and child mortality rates are responsible for increased demands for reversal of sterilisation. Proper pre-operative counselling, age of the women, assessment of marital stability, family size and age of children are important before advocating sterilisation as a method of contraception.
\end{abstract}

\section{Key words}

Indian women, profile, reversal, sterilisation, tubectomy

\section{Key message points}

- In India approximately 5-6 million women undergo sterilisation annually.

- Factors contributing to the increasing demand for reversal of tubectomy in India include early marriage of girls, early completion of desired family size and high infant and child mortality rates.

Proper councelling prior to sterilisation is important.

\section{Introduction}

Tubectomy is the most commonly accepted method of contraception in India, where approximately 5-6 million women undergo sterilisation annually. ${ }^{1}$ A large number of these women subsequently seek reversal. Due to sociocultural differences between the developed and developing countries, the profile of women seeking reversal and the reasons for which they request reversal are quite different in India as compared to developed countries.

\section{Method}

This was a prospective clinical study carried out in the Departments of Obstetrics and Gynaecology of the Pandit BDS Post Graduate Institute of Medical Sciences, Rohtak and Lady Hardinge Medical College, Delhi, from August 1994 to December 1998. The sample comprised 96 women who underwent tubectomy at peripheral primary care centres and were referred for microsurgical tubectomy reversal. All 96 women were subjected to a detailed questionnaire.

The objective of this study was to determine the profile of Indian women seeking reversal following tubectomy.

\section{Results}

The majority of the women (84\%) came from a conservative rural background, and lived in a joint family system. Most of them ( $86 \%$ ) belonged to an average socioeconomic status. Fifty-two percent of the women were illiterate. The husbands of $63 \%$ depended on farming to support their families.

The mean age of the women at the time of tubectomy was 24 (20-32) years and the mean family size was 2 (1-5). The mean age at the time of reversal was 28 (22-36) years, and the mean family size was $1(0-3)$. The reason for request for reversal was death of one or more children in all the patients. The time interval from the death of the child to request for reversal varied from 1.5 months to 7 years. Death of the male child was the deciding factor in $90 \%$ of women. A majority of the children (53\%) died due to infectious diseases. Twenty-five percent of the children died during infancy, and $38.6 \%$ died within 1 to 5 years of age.

\section{Discussion}

In India, tubectomy is a popular method of contraception. There is an ever-increasing demand for reversal of tubectomy. The various contributing factors include early marriage of girls (average age 19 years), early completion of desired family size due to a low contraceptive prevalence rate $(45 \%)$, and high infant and child mortality rates (74/1000 live births and 23.7/1000 live births, respectively). ${ }^{1}$

In developed countries, women marry late and opt for sterilisation late in their reproductive period. They seek reversal due to factors like unstable marriage, divorce, remarriage, psychological problems etc. ${ }^{2}$ This is in contrast to Indian women, who seek reversal mainly due to death of one or more children, especially a male child.

\section{Conclusion}

Adoption of tubectomy at a very young age, coupled with high infant and child mortality rates, are responsible for increasing demand for reversal of tubectomy in developing countries. Proper stress on pre-operative counselling and due consideration to factors like age of the women, assessment of marital stability, family size and age of children should be given before advocating sterilisation as a method of contraception.

\footnotetext{
Statements on funding and competing interests Funding. None.

Competing interests. None declared. 